\title{
Selection of the Approach to Developing Core Competitiveness of New Farmers
}

\author{
Aichen Liu \\ Jilin Agricultural University, Changchun 130118, China. \\ 9558805@qq.com
}

\begin{abstract}
The greatest efforts should be made to promote the core competitiveness of new farmers and develop new farmers since they are the most crucial and essential issue for building the new socialist rural area. Meanwhile, they are the most urgent issue among agriculture, rural area and farmer. The core competitiveness to be gained by new farmers is illustrated in this paper. Then symptoms and causes of the shortage of core competitiveness for new farmers nationwide are discussed. At last, the paper has proposed an approach to developing core competitiveness of new Chinese farmers, thus providing related authorities and departments with a model and reference.
\end{abstract}

Keywords: New farmers; core competitiveness; developing; approach.

\section{Introduction}

Farmer is a core among three major issues mentioned above. Developing new farmers plays an extraordinarily important role in the issue concerning farmers. In a long range, the fundamental solution to the development of agriculture and rural area lies in scientific progress and massive agricultural laborer having a good command of science \& technology and skills. In this view, lack of high-quality laborers will make it impossible to transform any advanced science \& technology into efficient productivity. Undeniably most farmers are at a lower scientific and education level and suffer from the weak core competitiveness. There is a big gap with the general requirements for building the new socialist rural area.

\section{Quality Analysis of New Farmers}

The modern agriculture requires a higher quality of Chinese farmers. In other words, Chinese farmers must get education, know technology, business and management, enjoy excellent physical quality and have strong sense of modernization. These aspects have constituted major factors influencing the core competitiveness of new farmers. Once armed with qualities as above, the new farmers will be more competitive than traditional farmers, thus making greater contribution to the modern agriculture development. As shown in Fig 1:

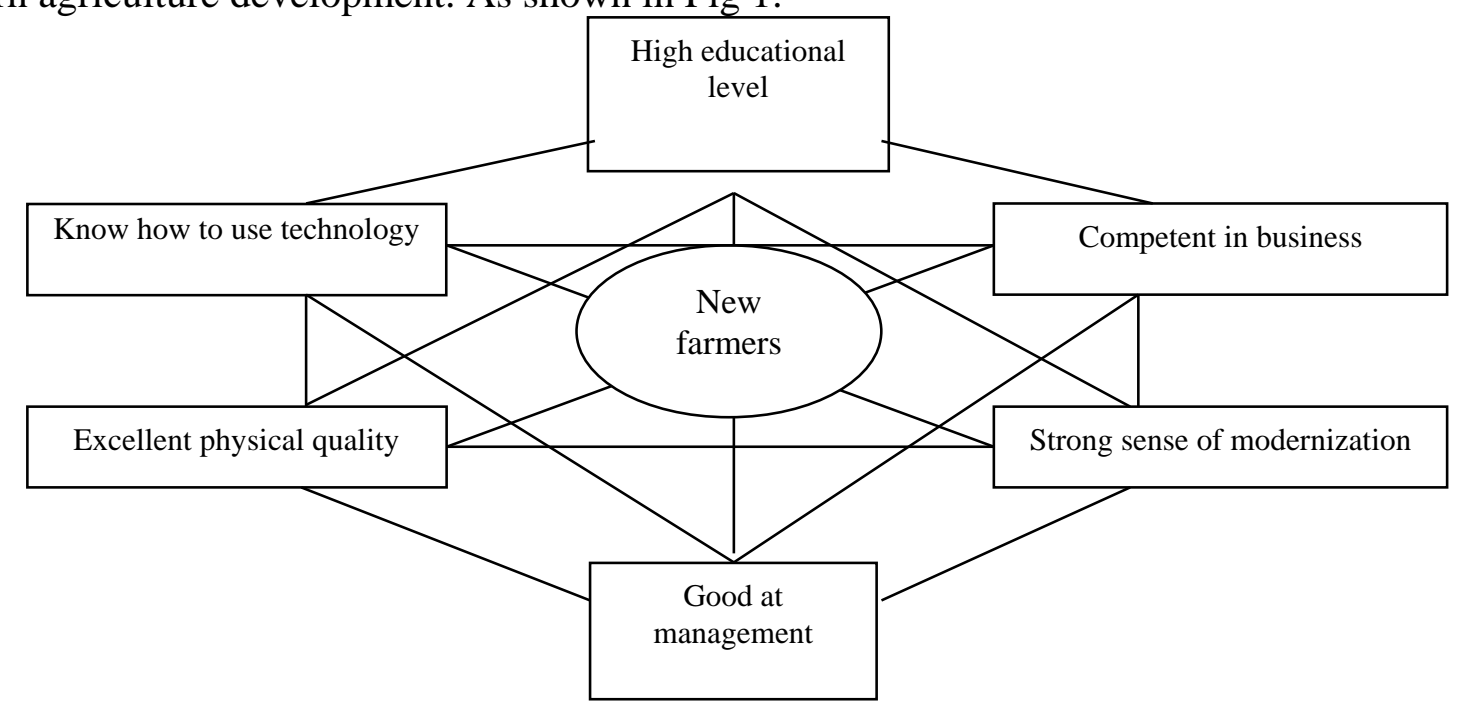

Fig. 1 Quality Analysis of New Farmers (Michael Porter Diamond Model) 


\section{Symptoms of Lack of Core Competitiveness for New Farmers}

The modern agricultural development has posed a higher requirement for the core competitiveness of new farmers. However, the Chinese farmers are still very weak in education level, science capability, business management capability, physical quality and sense of modernization.

\subsection{Education Level.}

Most Chinese rural areas see a profound accumulation of traditional cultures. Farmers are affected by such traditional cultures with their cultural values and outlooks restricted and dominated by the culture. Consequently, there is a big gap of educational level between urban residents and rural residents in the country. Furthermore, the education received by farmers is lagged far behind that received by urban residents. Rural areas are less covered by voluntary education, resulting in a weak foundation. According to a survey, the farmers from Jilin Province have only received 7 years of education on average, whereas this number is 10.8 for urban residents in the same period. See Fig 2 for details.

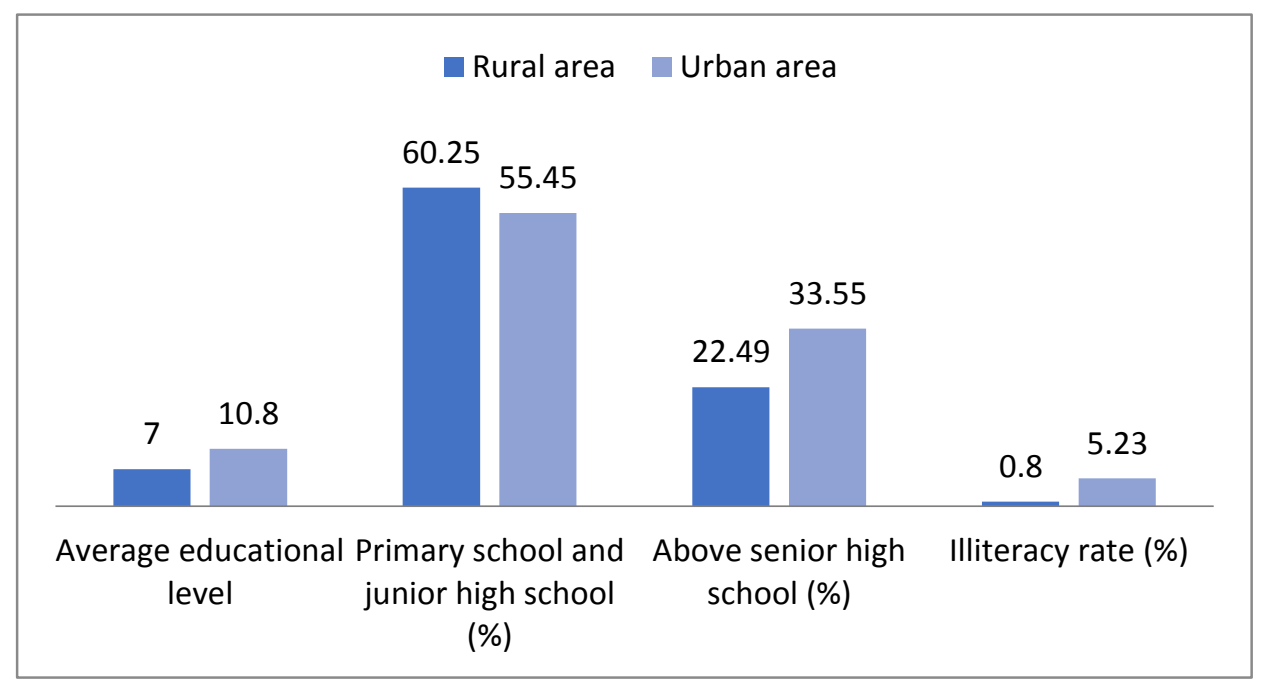

Fig. 2 Comparisons of Education Level between Urban Residents and Rural Residents; Data source: Survey of Jilin Province on trainings for farmers in August 2015 and the Statistical Yearbook of Jilin Province

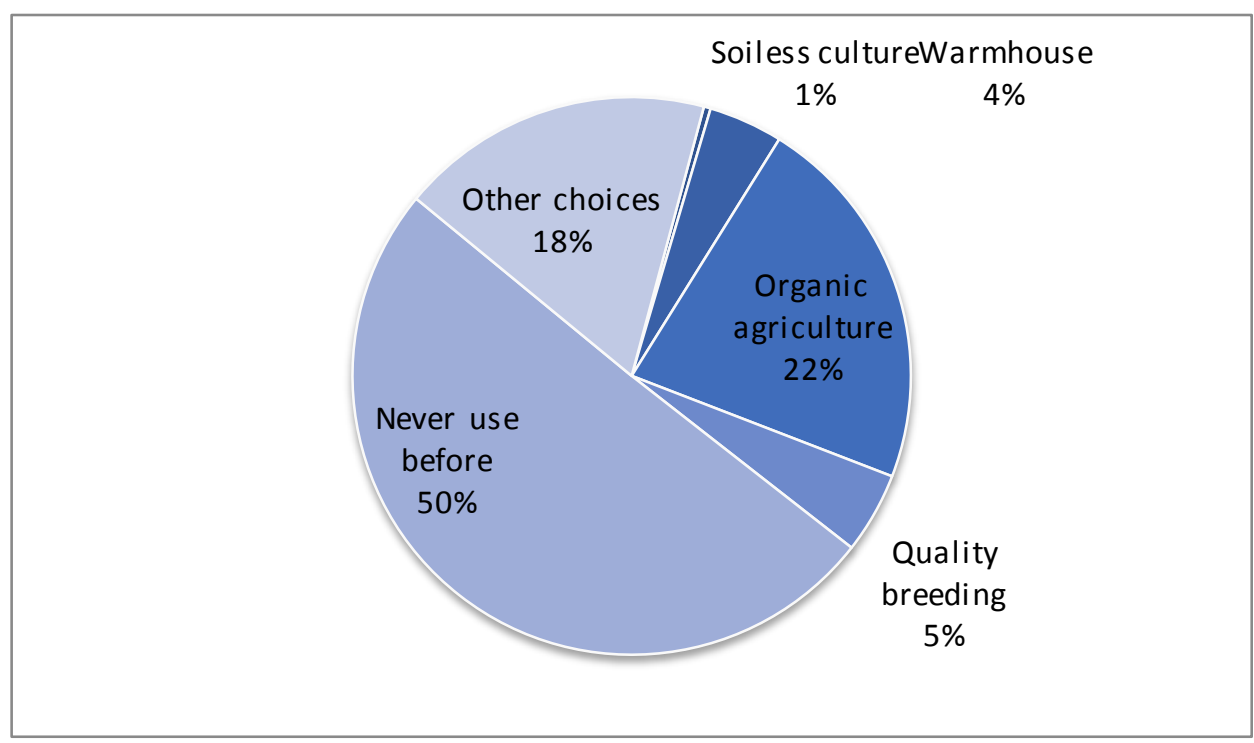

Fig. 3 Applications of Agricultural Science and Technology by Farmers of Jilin Province (\%); Data source: Survey of Jilin Province on trainings for farmers in August 2015

\subsection{Science Capability.}

At present, most Chinese farmers are still engaged in planting and only few farmers are specialized in livestock breeding and simple handicrafts. However they have only grasped some traditional and 
simple planting and breeding techniques. Information flows are not so smooth in rural areas, disabling local farmers to enjoy more advanced technologies. Even if some farmers have the chance to know these technologies, they are still unable to apply these technologies effectively because of their comprehensions and education levels. As shown by the survey, farmers of Jilin Province have seldom applied science and technology to agriculture. This fact will not only go against agricultural scale, industrialization and modernization but also set a barrier to the promotion of farmers' quality. See Fig 3 for details.

\subsection{Business and Management Capability.}

In our country, the rural market economy is relatively underdeveloped. Although the household contract responsibility system has remarkably mobilized farmers, farmers will inevitably encounter scattered business and small business scale after a long period of time, resulting in the lack of competitiveness and sense of organization. Only few farmers know business and management, whereas most farmers have not gained the sense of business and management, making themselves unable to participate in the market economy. Moreover, they have never received systematic educations and trainings on contemporary market economy. As a result, they are not active to enter the market. For example, most farmers of Jilin Province are not willing to enter markets and participate in market competitions during selling agricultural products due to the absence of business and management sense. They always prefer door-to-door purchase of agricultural products. Under such a circumstance, the sales channel is not diverse and the purchasers may intentionally reduce the purchase price, making farmers passive and embarrassed in the agricultural product transactions. See Fig 4 for details.

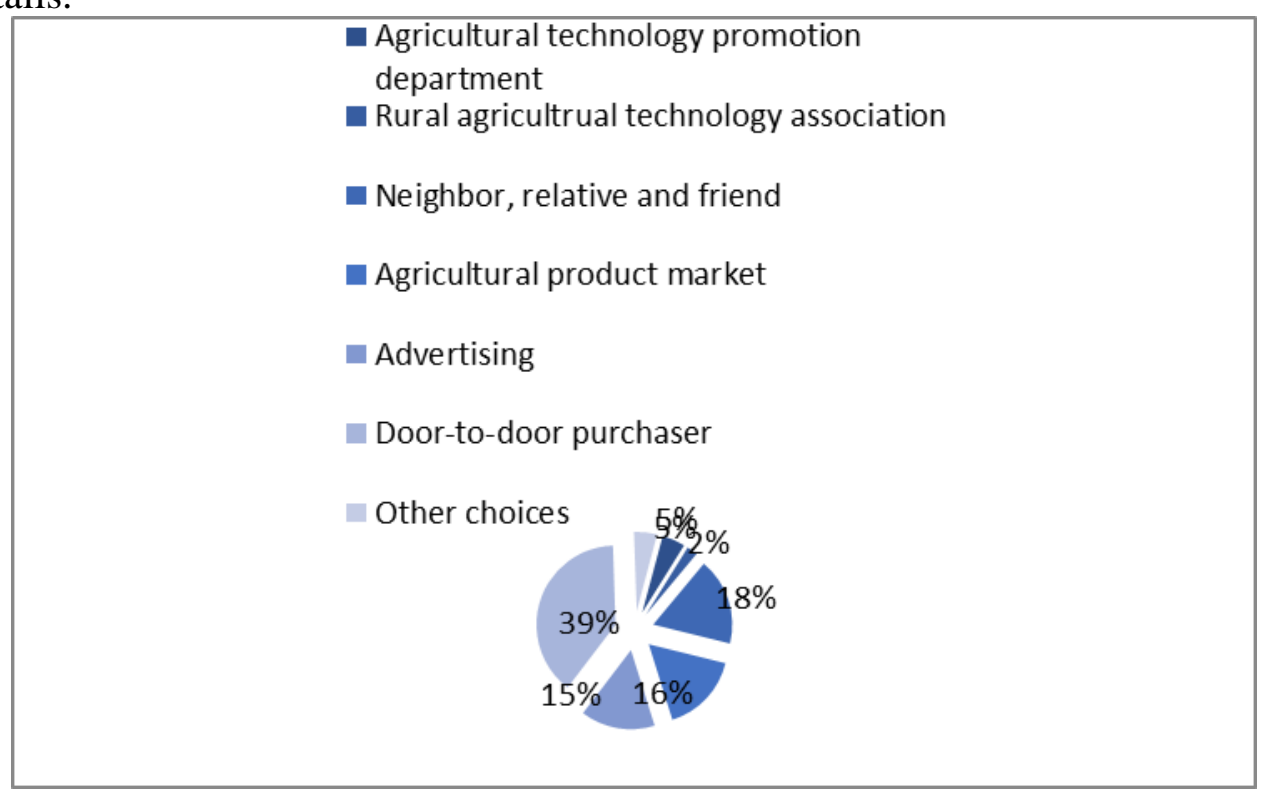

Fig. 4 Data Source for Farmers of Jilin Province to Sell Agricultural Products (\%); Data source: Survey of Jilin Province on trainings for farmers in August 2015

\section{Conclusion}

(1) Speed up the Process of Rural Education System Reform.

The ultimate solution to the promotion of farmers' core competitiveness lies in improving the rural education development and the farmers' level of science and culture. This solution requires all related professionals to strengthen the rural basic education development, give a top priority to the reform of rural basic education in the rural area development and tangibly realize the rural voluntary education. At the same time, all-level governmental departments should elaborate their rights and obligations in the rural voluntary education, actively take various measures to reform the traditional rural education system, guarantee the investment in rural basic education and create a good condition for the rural education. In addition, related governmental departments should work hard to promulgate relevant policies to promote the quality of rural basic education, reduce the percentage of students who are 
unable to go to school against all students eligible for voluntary education and the drop-out rate and lessen new illiteracies, thus bringing the rural basic education into full play, ultimately promoting cultural quality of farmers and developing them into "educated and cultured" new farmers.

(2) Strengthen Vocational Trainings for Farmers.

Firstly, it is proposed to create and consummate a new vocational training system for farmers. All related governmental departments should gain a deep understanding towards current needs of farmers for trainings and keep improving the vocational training system for farmers based on actual situations to create a new vocational training operation system for farmers with the government as planner, the agricultural department as leader, related departments as sponsor and all social classes as participants. Moreover, it is required to develop rural vocational vocational-technical schools to provide farmers with a training platform. Rural vocational vocational-technical schools serve as the most direct approach for farmers to new knowledge and technology. For this reason, it is necessary to train those new rural laborers who have only received education of junior and senior high school, and develop them into a real "technical" new farmer through teaching.

(3) Help Farmers Strengthen the Sense of Modernization.

Farmers play a main role in building the new socialist rural area. Therefore, integrate them into the modern trend as soon as possible to eliminate those adverse impacts brought by habitual thinking and traditional cultures to farmers. With the sustainable development of the socialist market economy system, farmers must face fierce market competitions, learn related agricultural technologies and even grasp knowledge on business and management if they want to increase their income. With reference to this fact, diversified measures must be taken to help farmers promote their sense of modernization and keep enriching their value outlook, thus developing them into real new farmers featuring the capability of business and management and the sense of modernization.

\section{References}

[1] Ni Hui, Wan Baofang and Gong Chunming. Study on the Global Experience and China's Practices in Developing New Professional Farmers [J]. World Agriculture, 2013, 03:134-137.

[2] Zhang Xue, Li Yi. Study on the Problems and Measures of Developing New Farmers in Hebei Province [J]. Continue Education Research, 2014, 12:21-23.

[3] LvJia. Study on Developing New Professional Farmers in the View of Modern Agriculture [J]. Hubei Agricultural Sciences, 2015, 04:1018-1022.

[4] Tong Jie, Li Hongwei and Qu Xihua. Trend of Developing New Professional Farmers in China and the Support System Construction [J]. Research on Financial and Economic Issues, 2015, 04:91-96. 